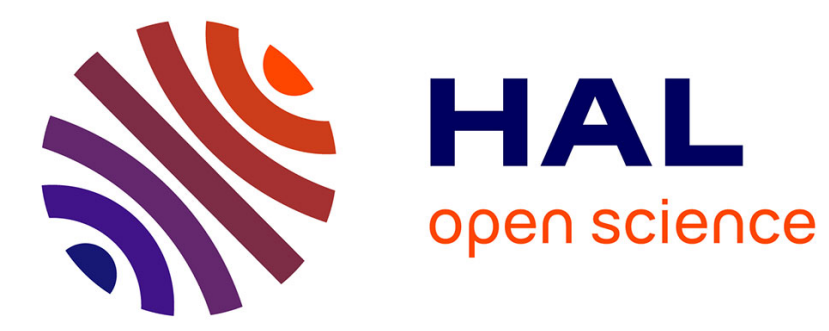

\title{
Temperature-driven phase transformation in self-assembled diphenylalanine peptide nanotubes
}

A Heredia, I Bdikin, S Kopyl, E Mishina, S Semin, A Sigov, K German, V Bystrov, a L Kholkin

\section{- To cite this version:}

A Heredia, I Bdikin, S Kopyl, E Mishina, S Semin, et al.. Temperature-driven phase transformation in self-assembled diphenylalanine peptide nanotubes. Journal of Physics D: Applied Physics, 2010, 43 (46), pp.462001. 10.1088/0022-3727/43/46/462001 . hal-00569745

\section{HAL Id: hal-00569745 \\ https://hal.science/hal-00569745}

Submitted on 25 Feb 2011

HAL is a multi-disciplinary open access archive for the deposit and dissemination of scientific research documents, whether they are published or not. The documents may come from teaching and research institutions in France or abroad, or from public or private research centers.
L'archive ouverte pluridisciplinaire HAL, est destinée au dépôt et à la diffusion de documents scientifiques de niveau recherche, publiés ou non, émanant des établissements d'enseignement et de recherche français ou étrangers, des laboratoires publics ou privés. 


\title{
Temperature-driven phase transformation in self-assembled diphenylalanine peptide nanotubes
}

\author{
A Heredia, ${ }^{1}$ I Bdikin ${ }^{2}$, S Kopyl ${ }^{2}$, E Mishina $^{3}$, S Semin $^{3}$, A Sigov $^{3}$ \\ K German $^{4}$, V Bystrov ${ }^{1,5}$ and A L Kholkin ${ }^{1 *}$ \\ ${ }^{1}$ Department of Ceramics and Glass Engineering \& CICECO, University of Aveiro, 3810-193 \\ Aveiro, Portugal \\ ${ }^{2}$ Centre for Mechanical Technology and Automation (TEMA), University of Aveiro, 3810-193 \\ Aveiro, Portugal \\ ${ }^{3}$ Moscow State Institute of Radioengineering, Electronics and Automation, 119454 Moscow, \\ Russia \\ ${ }^{4}$ Institute of Applied Physics, Kishinev, MD-2028, Republic of Moldova \\ ${ }^{5}$ Institute of Mathematical Problems of Biology, Puschino, Moscow district, Russia
}

E-mail: kholkin@ua.pt

\begin{abstract}
Diphenylalanine (FF) peptide nanotubes (PNTs) present a unique class of selfassembled functional biomaterials owing to a wide range of useful properties including nanostructural variability, mechanical rigidity, and chemical stability. In addition, a strong piezoelectric activity has been recently observed paving the way to their use as nanoscale sensors and actuators. In this work, we fabricated both horizontal and vertical FF PNTs and examined their optical second harmonic generation and local piezoresponse as a function of temperature. The measurements show gradual decrease of polarization with increasing temperature accompanied by irreversible phase transition into another crystalline phase at about $140-150{ }^{\circ} \mathrm{C}$. The results are corroborated by the molecular dynamic simulations predicting order-disorder phase transition into centrosymmetric (possibly, orthorhombic) phase with antiparallel polarization orientation in neighboring FF rings. Partial piezoresponse hysteresis indicates incomplete polarization switching due to high coercive field in FF PNTs.
\end{abstract}

Keywords:

diphenylalanine peptide nanotubes, piezoelectricity, second harmonic generation, phase transition 


\section{Introduction}

Piezoelectricity is the ability of crystalline materials without a centre of inversion to produce mechanical stress/strain under an electric field or charge/voltage under a mechanical force. This property is widely used nowadays in many applications including acoustic transducers, sensors/actuators, piezomotors, accelerometers and gyroscopes, just to name a few. ${ }^{1}$ Following current trends for miniaturization, piezoelectric materials were suggested to be the key elements of future micro- and nanoelectromecahnical systems (MEMS and NEMS), where piezoelectric effect offers many advantages over electrostatic actuation., ${ }^{2,3}$ In view of growing interest in biomedical applications, bioorganic materials having significant piezoactivity (in particular ferroelectrics ${ }^{4}$ ) are required for further progress in the design of modern piezo MEMS and NEMS. Several biologically originated materials were identified to be piezoelectric but their piezoelectric properties were rather weak to be used in applications. ${ }^{5,6}$ Another challenge is to fabricate the nanostructural material such as nanotubes for the activation of piezoelectricity at the nanoscale. ${ }^{7}$ Recently, strong piezoelectricity (of the order of that in the classical transducer material $\mathrm{LiNbO}_{3}$ ) has been discovered in bio-inspired peptide nanotubes (PNTs) made by a self-assembly process of small diphenylalanine, $\mathrm{NH}_{2}$-Phe-Phe-COOH (FF), peptide monomers. ${ }^{8}$ These PNTs have first been discovered from the determination of the smallest recognition motif of the amyloid- $\beta$ protein, associated with over 30 diseases, mostly neurodegenerative ones such as Alzheimer's, Huntington's, Parkinson's, CreutzfeldtJacob and prions, but also sclerosis (Lou Gehrig's disease) and type II diabetes. ${ }^{9}$ They are made from amino acids, self-assembled in unique stable tubes with hydrophilic hollows, ${ }^{10}$ having high Young's modulus and chemical stability. ${ }^{11} \mathrm{X}$-ray and electron diffraction have revealed that their room temperature crystal structure is compatible with the space group $P 6_{1}{ }^{12}$, allowing many physical phenomena described by the oddrank tensor, including optical second harmonics generation, pyroelectricity, linear electrooptic effect, piezoelectricity, etc. Crucial for applications is the temperature dependence of polarization in FF PNTs, and possible phase transformation under heating above room temperature. In this work, we present our recent findings on the temperature-dependent polarization response in FF PNTs, studied via Piezoresponse Force Microscopy (PFM) ${ }^{13}$ and optical SHG. 
Second harmonic generation (SHG) is known to be an efficient tool for studying different types of phase transitions, such as surface reconstruction of the collagen 3D configuration in teeth ${ }^{14}$, laser-induced melting, ${ }^{15}$ phase transitions in molecular monolayers, ${ }^{16}$ structural phase transition at the surface, ${ }^{17}$ etc. In ferroelectrics, diagnostics with SHG is based on the sensitivity of SHG intensity to the order parameter; therefore the temperature dependence of the square root of SHG intensity typically follows polarization behavior. In this way, various phase transitions in classical ferroelectrics ${ }^{18}$ as well as in organic materials ${ }^{19}$ were successfully identified. In organic materials, SHG is also sensitive to conformational transitions, including irreversible transformations. ${ }^{20}$ The aim of this work was thus to study temperaturedependendent SHG and PFM, with the focus on possible phase transitions and ferroelectricity in this material.

\section{Experimental details}

FF PNTs were self assembled by dissolving the FF dipeptide from the lyophilized form (Bachem, Switzerland) in 1,1,1,3,3,3-hexafluoro-2-propanol at a stock concentration of $100 \mathrm{mg} / \mathrm{ml}$. For horizontal tubes, $2 \mu \mathrm{l}$ of the stock solution was diluted with $98 \mu \mathrm{l}$ of dd$\mathrm{H}_{2} \mathrm{O}$. The diluted solution was deposited onto Au- or Pt-coated silicon substrates and left overnight for drying. For vertical tubes, $30 \mu \mathrm{l}$ of the stock solution was cast directly on a substrate with an area $\approx 2 \mathrm{~cm}^{2}$ and left for complete evaporation for $12 \mathrm{hrs} .{ }^{21}$ The local piezoresponse measurements were performed with a commercial AFM (Ntegra Prima, NT-MDT) equipped with external function generator and lock-in amplifier as already described elsewhere. ${ }^{8}$ We used doped Si cantilevers with the spring constants of $0.5-1 \mathrm{~N} / \mathrm{m}$. Ac voltage of $2 \mathrm{~V}$ amplitude and frequency $5 \mathrm{kHz}$ was applied to the counter electrode while the tip was grounded. For the SHG measurements, the beam of a Ti:sapphire laser $(790 \mathrm{~nm}$ with a pulse width of about $100 \mathrm{fs}$, a repetition rate of 80 $\mathrm{MHz}$, and an average power of $15 \mathrm{~mW}$ ) was focused onto a spot of about $50 \mu \mathrm{m}$ diameter. Reflection geometry was used at a $45^{\circ}$ incidence. Both fundamental and SHG waves were polarized with the electric field vector in the incidence plane ( $\mathrm{p}$-in, $\mathrm{p}$-out). The SHG signal at $380 \mathrm{~nm}$ was filtered by a colour filter (BG39) and detected by a photomultiplier tube in a photon counting mode. SHG images filtered by BG39 were taken with CCD camera using optical microscope (magnification $\mathrm{x} 45$ ) under 
femtosecond laser irradiation. CCD camera was then mechanically scanned to acquire the SHG image with the resolution of a few $\mu \mathrm{m}$.

\section{Results and discussion}

Figure 1 shows representative SEM and PFM images of the fabricated PNTs assembled horizontally and vertically on metallized substrates as described above. A variety of tubes of different lengths, diameters, and orientations was observed. Strong piezoelectric contrast was observed on both horizontal (via lateral PFM signal, inset to Fig. 1a) and vertical tube assemblies (via vertical PFM, inset to Fig. 1b). These results confirm already published $\operatorname{data}^{8}$ on horizontal tubes where only shear piezoelectric coefficient $\left(d_{15} \sim 60 \mathrm{pm} / \mathrm{V}\right.$ on sufficiently big tubes) could be measured. The estimate of the effective longitudinal piezoelectric coefficient $d_{33}$ in vertical tubes yields values in excess of $30 \mathrm{pm} / \mathrm{V}$, i.e. it exceeded that for $\mathrm{LiNbO}_{3}{ }^{22}$ Figure 2 a represents the variation of the average shear PFM contrast with increasing temperature measured on horizontal tubes. The contrast gradually decreases with temperature demonstrating monotonous $d_{15}$ dependence and ultimate disappearance of piezoresponse at the temperature of $\sim 150{ }^{\circ} \mathrm{C}$. It should be noted that the contrast becomes irreversible if the sample is heated above $100{ }^{\circ} \mathrm{C}$, i.e., it is not recovered after cooling down to room temperature and remained practically zero after heating up to $140-150{ }^{\circ} \mathrm{C}$. This hints to the possible phase transformation to another phase on heating, as no visible degradation of the topography was found. Figure $2 b$ shows the temperature dependence of SHG intensity measured on vertical tubes (both heating and cooling runs). The results are, in general, consistent with the temperature-dependent PFM contrast measurements, however, many more details were observed on the temperature curve. A clear cusp on the SHG intensity curve at about $50{ }^{\circ} \mathrm{C}$ is followed by the significant reduction of the intensity until a plateau between 100 and $120^{\circ} \mathrm{C}$ is reached. Finally, the SHG signal drops down at $\sim 130$ ${ }^{\circ} \mathrm{C}$ (irreversibly as evidenced by the cooling curve). It should be noted that these data are consistent with the recent studies of thermal stability of PNTs via differential thermal gravimetry (DTG). ${ }^{23}$ These measurements revealed that FF PNTs exhibit a clear weight loss at temperatures close to $\sim 50{ }^{\circ} \mathrm{C}$ (anomaly seen also with SHG, Fig. 2b) and at $\sim 140{ }^{\circ} \mathrm{C}$. The rearrangement of the crystalline structure of PNTs at $50{ }^{\circ} \mathrm{C}$ (as evidenced by the anomaly of the SHG signal) can be due to the phase transition between 
two piezoelectric phases as confirmed by the existence of piezoresponse both below and above this temperature (Fig. 2a). The details of this phase transition are outside the scope of this paper and will be reported elsewhere. In general, the apparent decrease of the piezoelectric contrast and SHG intensity (Fig. 2) with temperature is a clear signature of the irreversible phase transformation into a high-symmetry phase as often observed in molecular crystals. ${ }^{24,25}$

Figure 3 shows typical x-ray diffraction patterns of the studied vertical PNTs before and after temperature annealing at $150{ }^{\circ} \mathrm{C}$ during 1 hour. In virgin samples (grown at room temperature) all observed peaks correspond to the expected hexagonal

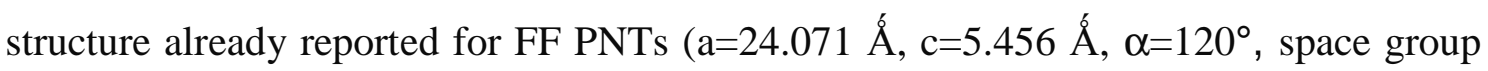
$\left.P 6_{1}\right) .{ }^{12}$ The diffraction peaks for annealed PNTs are apparently different, belonging to another crystalline phase. All diffraction peaks after annealing could be explained based on the appearance of an orthorhombic structure with the unit cell parameters: $a=5.210$ $\AA$, $b=24.147 \AA$, c=41.072 $\AA$ (see Table 1 of the Supplementary Material section for more details). The possible phase transition between hexagonal and orthorhombic phases upon annealing is illustrated in Figs. $4 \mathrm{~b}$ and $4 \mathrm{c}$, where it is shown how the initial hexagonal unit cell could be transformed into the orthorhombic one via a small deformation of the FF rings. The mainframe of the FF PNT structure consists of the FF rings (Fig. 4a), formed from six individual FF molecules (6FF), in accordance with Ref. 12. Each ring possesses a dipole moment $P_{\mathrm{s}}$ along tubular $\mathrm{OZ}$ axis perpendicular to ring plane and form the hexagonal structure ${ }^{12}$ from four rings (Fig. 4a, right). It is suggested that for the hexagonal structure all 6FF rings (A, B, C, and D) have the same orientation as the individual $P_{\mathrm{s}}$ (Fig. $4 \mathrm{~b}$ ), this being compatible with the total large dipole moment and strong piezoresponse in PNTs grown at room temperature. ${ }^{8}$ Antiparallel orientation of $P_{\mathrm{s}}$ for the neighboring 6FF rings (A and $\mathrm{C}$ opposite to $\mathrm{B}$ and $\mathrm{D}$ ) produces novel orthorhombic structure with zero total polarization (Fig. 4c) for annealed tubes.

To understand further the molecular structure of the FF PNTs and possible mechanisms of their self-assembly and phase transitions, we performed molecular modeling and molecular dynamic (MD) simulations using HypeChem 7.52. ${ }^{26}$ The isolated ring with six dipeptides as well the parallel stacking of two rings (see Fig. S1 of the Supplementary Material section) were studied by the geometry optimization of the total energy and MD runs using molecular mechanics (MM) methods (BIO CHARM) in combination with first principle quantum approach (ab initio and PM3 semi-empirical). It was found that $6 \mathrm{FF}$ forms ordered rings (hexagonal structure, $P 6_{1}$ ) with inner and 
outer diameters of $\sim 10.5$ and $25 \AA$, respectively, connected by N-H...O hydrogen bonds with O-H lengths of $\sim 1.65 \AA$. This is in full agreement with the results of Ref.12. Further, we calculated the dipole moment being $~ 1.3$ Debye for a single 6FF ring, directed along the OZ hexagonal axis corresponding to a spontaneous polarization $\mathrm{P} \approx 0.24 \mu \mathrm{C} / \mathrm{cm}^{2}$. This data also corresponds to the reported values for isolated FF units ${ }^{12}$ (Fig. 4a). Figure S1 represents the model of parallel double-stacked 6FF units. In this case, the optimization with BIO CHARM (after PM3 calculations) leads to a large dipole moment $\mathrm{D}_{\mathrm{t}} \sim 42$ Debye $\left(\mathrm{P} \sim 4.0 \mu \mathrm{C} / \mathrm{cm}^{2}\right)$. After additional PM3 semi-empirical optimization it further increases up to $\mathrm{D}_{\mathrm{t}} \sim 52$ Debye and the estimated polarization value reaches $\sim 5 \mu \mathrm{C} / \mathrm{cm}^{2}$. On the basis of this model we performed MD runs and simulations at different temperatures. The result is fully consistent with the experimentally obtained SHG and PFM data, i.e., the average dipole moment gradually decreases as a function of temperature (cf. calculations with experimental data in Fig. 2b). The polarization is about $5 \mu \mathrm{C} / \mathrm{cm}^{2}$ at $25^{\circ} \mathrm{C}$ and decreases to $\sim 2 \mu \mathrm{C} / \mathrm{cm}^{2}$ at $100{ }^{\circ} \mathrm{C}$. The results for a parallel stacked FF ring model correspond to the hexagonal phase and the experimentally observed large dipole moment and high piezoelectric coefficient in virgin structures, while the antiparallel orientation of neighboring tubes correspond to the orthorhombic phase with a very small total dipole moment, as is shown in Fig. $2 b$. Moreover, this result made us believe that the dipole ordering along OZ hexagonal axis for the hexagonal phase is due to a cooperative dipole effect (as common to ferroelectric systems, while the orthorhombic phase is similar to antiferroelectrics), and polarization switching is possible if a high-enough electric field is applied along this axis.

Following this idea, we attempted to measure piezoresponse hysteresis on virgin (not annealed) vertical PNTs. The simulation data has led to the conclusion that the corresponding coercive field would be very high, in the order of $\sim 30 \mathrm{MV} / \mathrm{cm}$, and have an asymmetric character as a result of the strong internal bias field. This prediction is fully consistent with the experimental result (Fig. 5) where a hysteretic-like dependence of the effective $d_{33}$ vs. applied bias is obvious. However, the loop reveals partial switching of the polarization along the hexagonal axis with superimposed linear behaviour that could be caused by the electrostatic contribution to the piezoresponse (Maxwell stress). ${ }^{27}$ Taking into account some flexibility of the PNTs at the contact point, and apparent non-local electrostatic interaction, this possibility cannot be ruled out. The results are in line with recent piezoresponse measurements in PZT nanotubes where a similar character of the piezoresponse hysteresis was found. ${ }^{28}$ This signifies 
that the local measurements in such complex geometries can be overshadowed by the spurious signals irrespective of the nature of the material. The polarization offset observed in the hysteresis loops (Fig. 5) could be due to the fact that the available electric field is insufficient for switching, and only a small reverse domain (unstable with time) is formed under a maximum bias. This is confirmed by the absence of any switched polarization after the consequent PFM imaging. Since the available electric field by the tip is quite low (in the first approximation $\sim 100-200 \mathrm{kV} / \mathrm{cm}$ under the bias $10 \mathrm{~V}$ ), this reduces the opportunities for using vertical FF PNTs as media for high density data storage. Unfortunately, higher biases destroy the tubes. Molecular simulations made under electric field were in line with the experimental observation (Table 3 of the Supplementary Material section) and showed that the antiparalle field of about $5 \mathrm{MV} / \mathrm{cm}$ is only able to decrease polarization value by about $12 \%$.

Another important result of our simulations is the tentative explanation of the observed hexagonal-orthorhombic irreversible transformation, because the calculations show that the temperature increase leads to the strong changes in the condensation energies, in particularly modifying inter-tube interaction. The approach for the intertube interaction calculations with distances and determination of the condensation energies is similar to that used in Ref. 29. As a result, the inter-tube condensation energy is decreasing with temperature and, at the temperature of about $150{ }^{\circ} \mathrm{C}$, it becomes comparable with thermal energy kT (Fig. S1, Table 2). This ultimately leads to the dissociation of PNT tubes and reorganization of their structure, so that the antiparallel orientation of the rings becomes energetically favorable at high enough temperature. All in all, the predicted re-orientation of polar molecular dipole groups in neighboring FF tubes leads to the compensation of the total polarization to almost zero value, accompanied with the symmetry change and increase of the unit cell size (see, for illustration Figs. 4 and S1 and Tables 1 and 2 of the Supplementary Material section). We believe that for FF PNTs prepared at room temperature, the parallel orientation of the polar moments related to individual nanotubes is energetically favorable; while at $\mathrm{T}$ $\geq 150{ }^{\circ} \mathrm{C}$ the preferred conformation is anti-parallel leading to a doubling of the unit cell. This model is in line with the experimental XRD results (Fig. 3) and the orthorhombic structure shown in Fig. 4. Upon cooling this phase persists down to room temperature, being metastable within extended period of time. The calculated transition temperature is close to that observed by PFM and SHG experiments. AFM and SEM 
data (Fig. S2 of the Supplementary Material section) indicate notable degradation of the tube surface consistent with earlier reports. ${ }^{30}$

It is already well known that FF peptides could form various supra-molecular structures. One of the most studied conformations is a hexagonal molecular nanotube structure, similar to that observed in liquid crystals (LC). ${ }^{31,32}$ From this point of view it is evident that the studied PNTs could be considered as an analog of a smectic $\mathrm{C}^{*}$ (SmC*) phase, composed of six FF L-chiral molecules arranged as a single 6FF stable ring (one smectic disc further forms discotic-like columnar structure ${ }^{24,33}$ ). Obviously, such molecular LC is prone to polymorphic transformations ${ }^{25}$ that occur due to a very wide variation of the peptide's bond torsion angle. Some of these polymorphic phases could be metastable leading to possible irreversible phase transitions. It is worth noting that structural polymorphism exists in the amyloid fibrils related to PNTs ${ }^{34}$. Similar transitions were observed in the temperature dependence of LC lipid systems ${ }^{35}$ and in DNAs that change from tubular hexagonal to orthorhombic structure ${ }^{36}$. It is clear that our results resemble the well-known phase transition in LC from ferroelectric-like SmC* to paraelectric SmA phase. The details of the molecular simulations and calculations of the condensation energies are reserved for future publication.

\section{Conclusions}

In conclusion, our measurements revealed an important feature of the polarization behavior in self-assembled diphenylalanine peptide nanotubes. As confirmed by the PFM and SHG measurements, the polarization gradually decreases from room temperature to $140{ }^{\circ} \mathrm{C}$, and experiences irreversible phase transformation to another (probably orthorhombic) crystalline phase with zero polarization. This phase persists upon cooling to room temperature. Partial polarization switching is observed by the application of a strong electric bias to the PFM tip, but full switching is impossible due to the high coercive field. This result is in line with the fact that ferroelectric-like behavior is originated from hydrogen bonds among the FF monomers, which break upon the temperature increase. This transformation is extremely important in view of the foreseeable applications of PNTs as sensors and actuators.

\section{Acknowledgements}


The work is supported by the Ministry of Science and Education of Russian Federation (contract $\mathrm{N}^{\mathrm{o}}$ 02.740.11.5060). VB is thankful to FCT (Portugal) for the partial financial support through his grant SFRH/BPD/22230/2005.

\section{References:}

[1] Safari A and Akdogan K (ed) 2008 Piezoelectric and Acoustic Materials for Transducer Applications (New York: Springer)

[2] Polla D L and Francis L F 2006 MRS Bulletin 2134

[3] Muralt P 2008 J. Am. Ceram. Soc. 911385

[4] Horiuchi S and Tokura Y 2008 Nat. Mater. 7357

[5] Fukada E and Yasuda I 1957 J. Phys. Soc. Japan 121158

[6] Halperin C, Mutchnik S, Agronin A, Molotskii M, Urenski P, Salai M and Rosenman G 2004 Nano Lett. 4 1253; Rodriguez B J, Kalinin S V, Shin J, Jesse S, Grichko V, Thundat T, Baddorf A P and.Gruverman A 2006 J. Struct. Biol. 153151

[7] Wang Z L 2007 Mater. Today 1020

[8] Kholkin A L, Amdursky N, Bdikin I, Gazit E and Rosenman G 2010 ACS Nano 4 610

[9] Harkany T, Hortobágyi T, Sasvári M, Kónya C, Penke B, Luiten P G M and Nyakas C 1999 Prog. Neuropsychopharmacol. Biol. Psychiatry 23963

[10] Reches M and Gazit E 2003 Science 300625

[11] Kol N, Adler-Abramovich L, Barlam D, Shneck R Z, Gazit E and Rousso I 2005 Nano Lett. 51343

[12] Görbitz C H 2001 Chem. Eur. J. 75153

[13] Bonnell D A, Kalinin S V, Kholkin A L and Gruverman A 2008 MRS Bull 34, 648;

Kalinin S V, Setter N and Kholkin A L ibid p 634

[14] Hoefer U, Li L, Ratzlaff G A and Heinz T F 1995 Phys. Rev. B 525264

[15] Shank C V, Yen R and Hirlimann S 1983 Phys. Rev. Lett. 51900

[16] Rasing Th, Shen Y R, Kim M W and Grubb S 1985 Phys. Rev. Lett. 552903

[17] Mishina E D, Misuryaev T V, Sherstyuk N E, Lemanov V V, Morozov A I, Sigov A S and Rasing Th 2000 Phys. Rev. Lett. 853664 
[18] Aktsipetrov O A, Apukhtina S A, Nikulin A A, Vorotilov K A, Mishina E D and Sigov A S 1991 JETP Lett. 54563

[19] Aktsipetrov O A, Misuryaev T V, Murzina T V, Blinov L M, Fridkin V M and Palto S P 2000 Opt. Lett. 25411

[20] Theodossiou T A, Thrasivoulou C, Ekwobi C and Becker D L 2006Biophys. J. 91 4665

[21] Reches M and Gazit E 2006 Nat. Nanotechnol. 1195

[22] Landolt H. and Bornstein R 1981 Numerical Data and Functional Relationships in Science and Technology (New Series) vol. III/16 (Berlin: Springer Verlag)

[23] Adler-Abramovich L, Reches M, Sedman V L, Allen S, Tendler S J B and Gazit E 2006 Langmuir 221313

[24] deGennes P G and Prost J 1993 The Physics of Liquid Crystals (Oxford:

Clarendon)

[25] Bernstein J 2002 Polymorphism in Molecular Crystals (Oxford: Clarendon)

[26] HyperChem.7.52. 2002 Tools for Molecular Modeling Hypercube Inc

[27] Hong S, Woo J, Shin H, Jeon J U, Pak Y E, Colla E L, Setter N, Kim E and No K 2001 J. Appl. Phys. 891377

[28] Scott J F, Fan H J, Kawasaki S, Banys J, Ivanov M, Macutkevic J, Blinc R, Laguta V V, Cevc P, Liu J S and Kholkin A L 2008 Nano Lett. 84404

[29] Nakanishi T, Okamoto H, Nagai Y and Takeda K 2002 Phys. Rev. B 66165417

[30] Sedman V L, Adler-Abramovich L, Allen S, Gazit E and Tendler S J B 2006 J. Am. Chem. Soc. 1286903

[31] Scanlon S and Angelli A 2008 Nano Today 322

[32] Yan X, Zhua P and Li J 2010 Chem Soc. Lett. 391861

[33] Saez I M and Goodby J W 2005 J. Mater. Chem. 1526

[34] Fandrich M, Meinhardt J and Grigorieff N 2009 Prion 389

[35] Raudenkolba S, Wartewigb S and Neuberta R H H 2005 Chem. Phys. Lipids 133 89 


\section{Figure captions:}

Figure 1. Representative SEM images of horizontal (a) and vertical (b) peptide nanotubes deposited from the solution. The insets show representative PFM in-plane (a) and out-of-plane (b) contrasts. PFM measurements on vertical tubes were actually performed on agglomerated tubes where scanning in contact mode was only possible.

Figure 2. Temperature dependencies of SHG (a) and PFM signals (b) for FF PNTs. The data points on SHG curves are compared with the MD calculations undertaken for parallel double-stacked FF in the hexagonal phase (triangles) and anti-parallel ones in the orthorhombic phase (diamonds).

Figure 3. X-ray diffraction spectra of FF PNTs before and after annealing at $150^{\circ} \mathrm{C}$ during 1 hour. Red bars are generated using structural data from CCDC file $\mathrm{n}^{\circ} 163340$.

Figure 4. (a) Schematic illustration of the self-assembly process of PNTs: from individual diphenylalanine (FF) monomer molecules to six dipeptides (6FF) forming a ring and finally to whole structure of peptide nanotubes. Models of the hexagonal (b) and orthorhombic (c) structures of PNTs (detailed explanation is given in the text).

Figure 5. Out-of-plane piezoresponse hysteresis taken on vertical PNTs. The piezoresponse signal does not change sign even at a maximum bias due to the high coercive field of hexagonal structure. 


\section{Supplementary Material}

Figure S1. Molecular model of the FF ring and double-ring formation leading to the large cooperative dipole moment in PNT structure (a), depending on the inter-ring (r) and inter-tube (R) distances schematically shown in (a) and (c). Calculated variation of inter-tube condensation energy $\boldsymbol{E}_{\boldsymbol{c o n}}$ with distance $\boldsymbol{R}$ (b) and comparison of minimum energy distances for two different temperatures for parallel (hexagonal) and anti-parallel (orthorhombic) structures of PNTs (inset). Here the yellow tube denotes schematic presentation for tubular coil of main molecular unit $\mathrm{NH} 2-\ldots-\mathrm{COOH}$.

Figure S2. (a) Representative topography and piezoresponse (in-plane) images of horizontal peptide nanotubes after different annealing temperatures. (b) SEM images of horizontal peptide nanotubes before and after annealing at $150{ }^{\circ} \mathrm{C}, 1 \mathrm{hr}$.

Table 1. Comparison of calculated and observed interplane distances $\left(\mathrm{d}_{\mathrm{cal}}\right.$ and $\left.\mathrm{d}_{\mathrm{obs}}\right)$ and observed relative integrated intensities $\left(\mathrm{I}_{\mathrm{obs}}\right)$ for Debye-Scherrer reflections for the annealed $\left(150^{\circ} \mathrm{C}, 1 \mathrm{~h}\right)$ sample. Orthorhombic unit cell: $a=5.210 \AA \hat{\alpha}, b=24.147 \AA$, $c=41.072$ Á. Space group: Pmmm (no. 47).

Table 2. Condensation energies and optimized distances at different temperatures.

Table 3. Calculation of electric field effect for 2-rings PNT model using UHF PM3 method and HyperChem 8.0. 

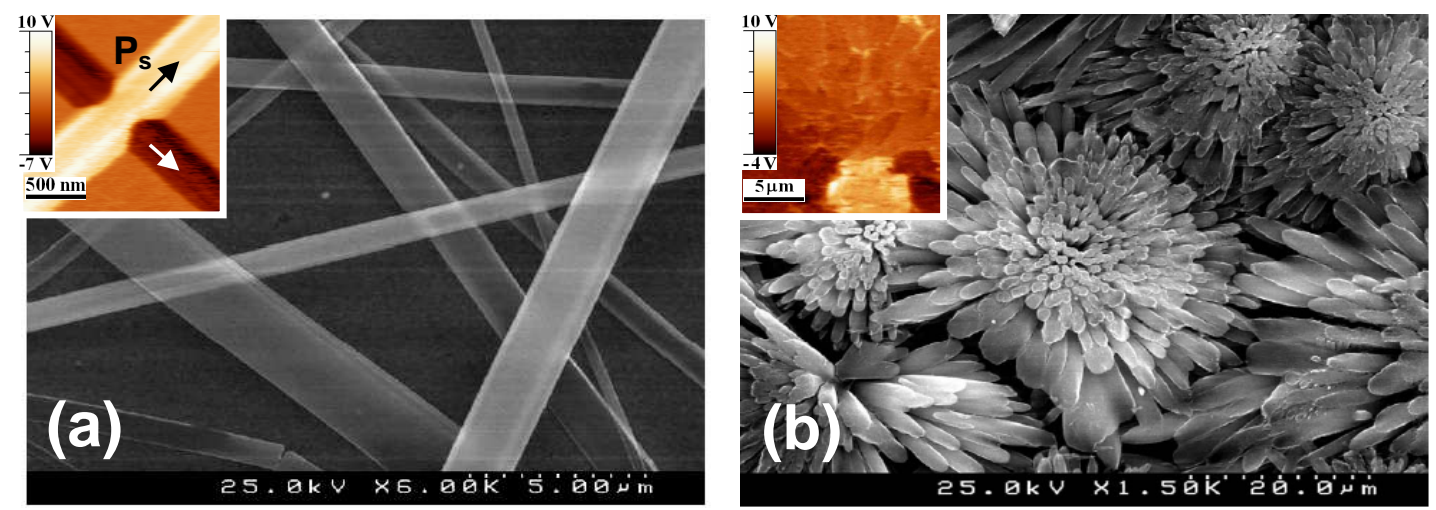

Figure 1. Heredia et al. 

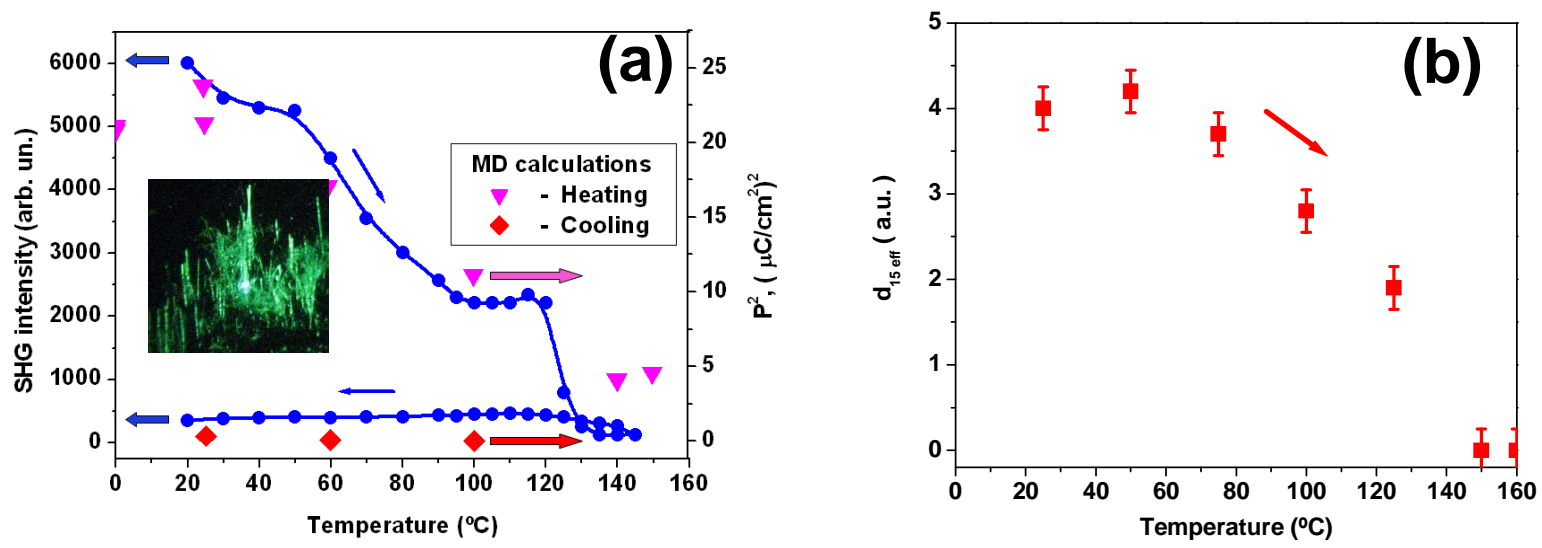

Figure 2. Heredia et al. 


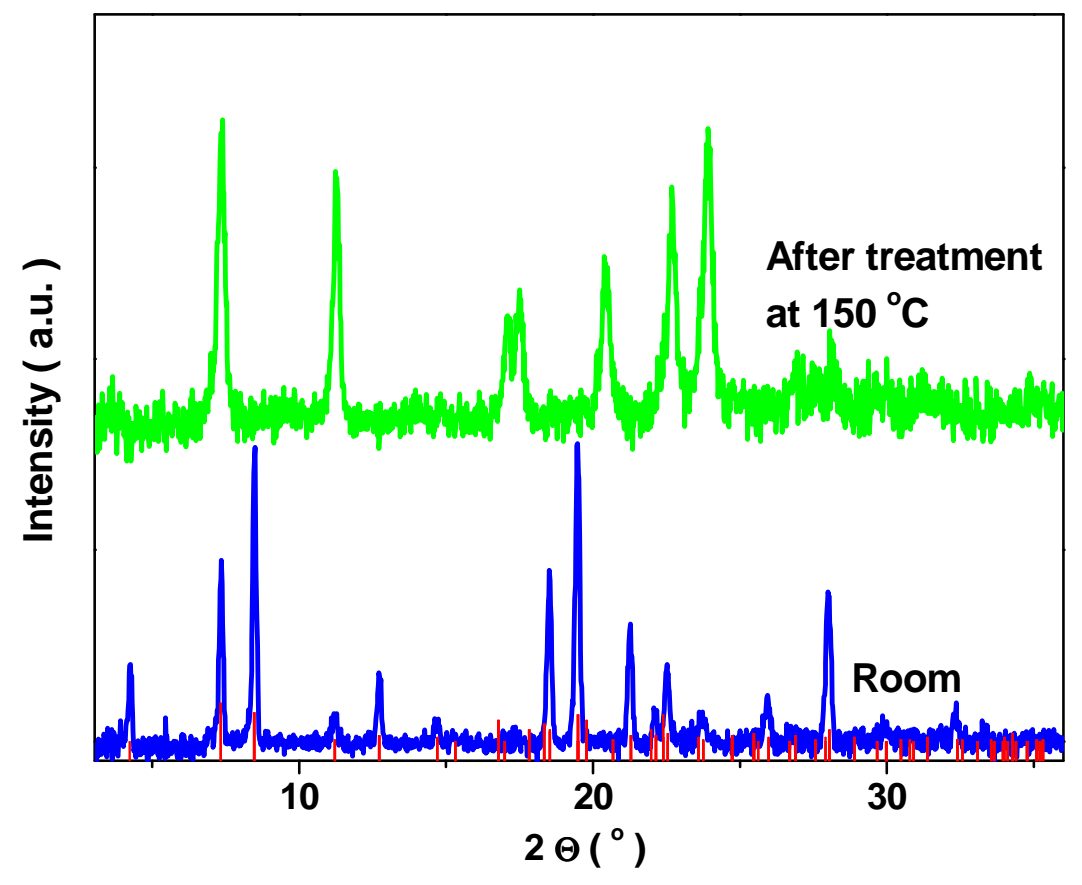

Figure 3. Heredia et al. 

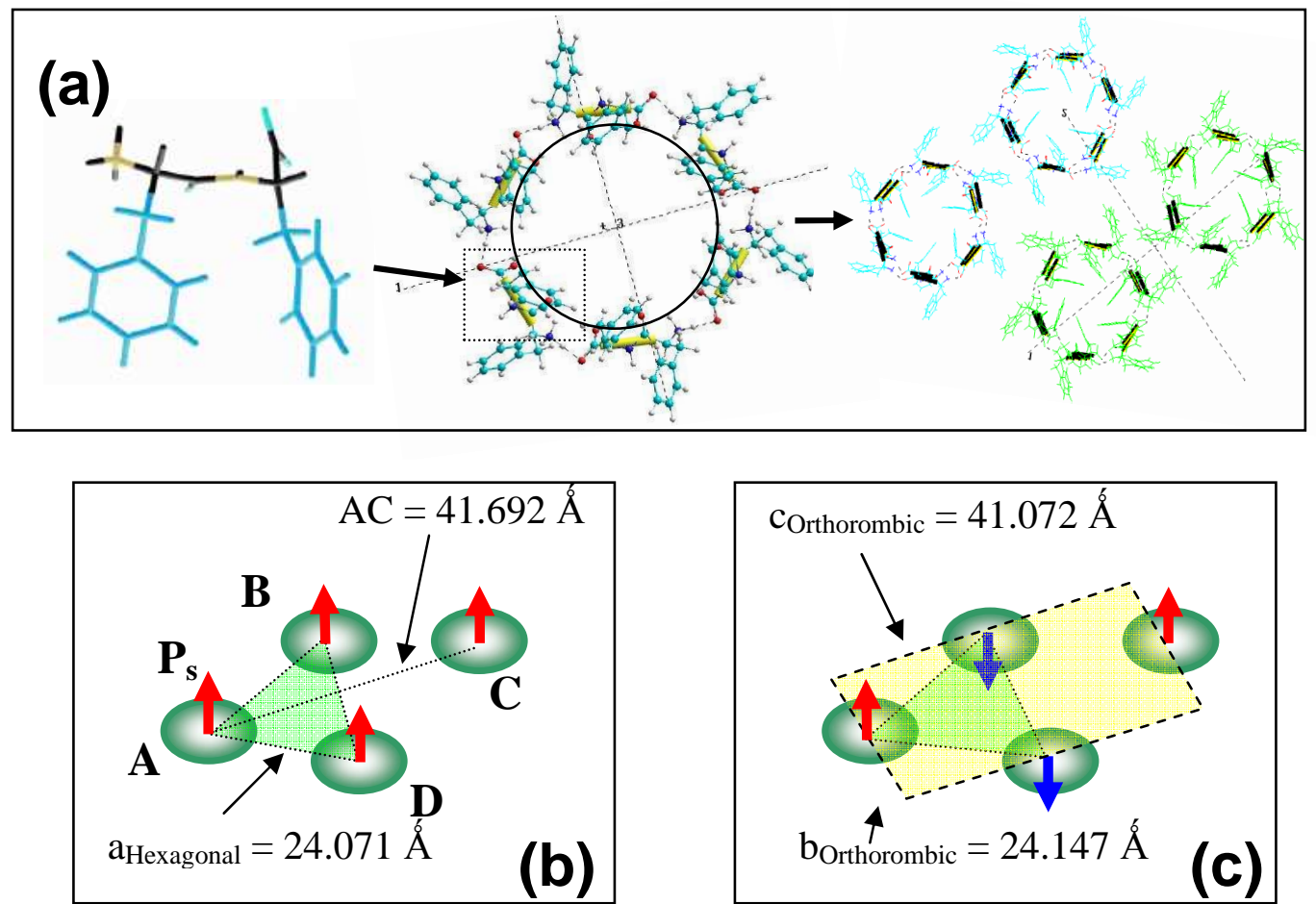

Figure 4. Heredia et al. 


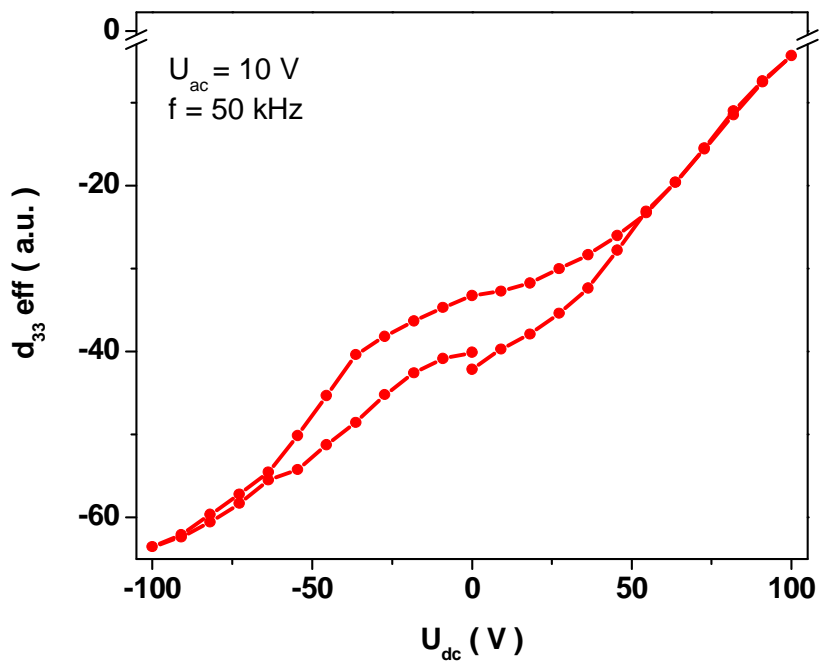

Figure 5. Heredia et al. 


\section{Supplementary Material}

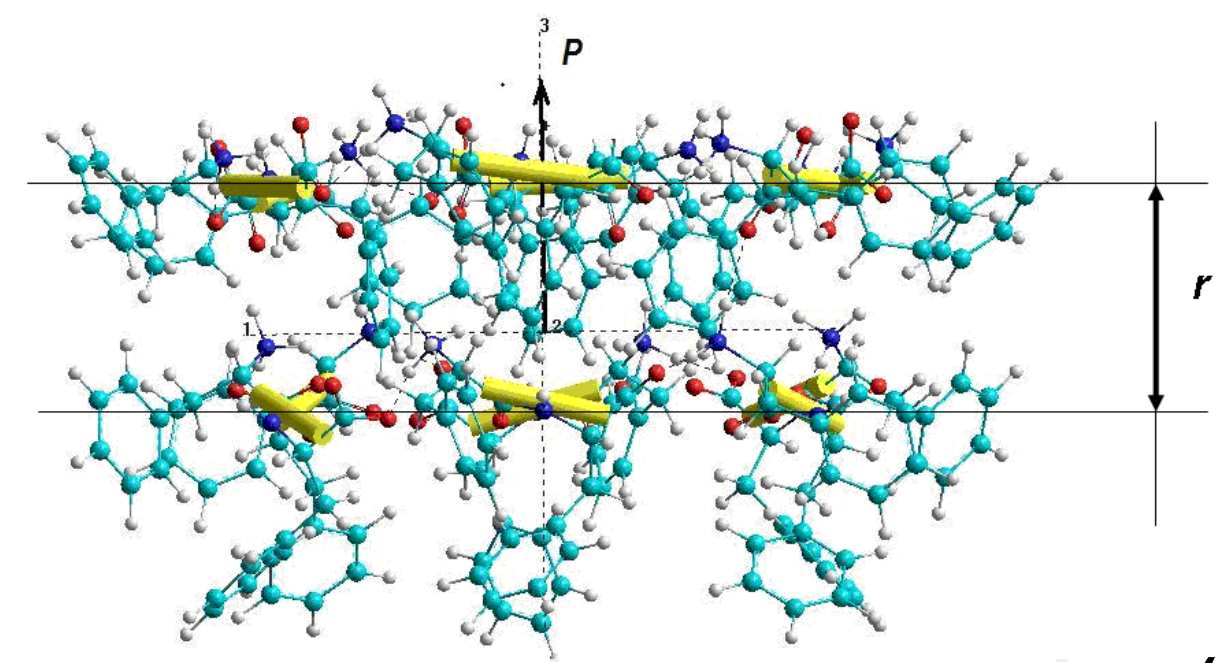

(a)
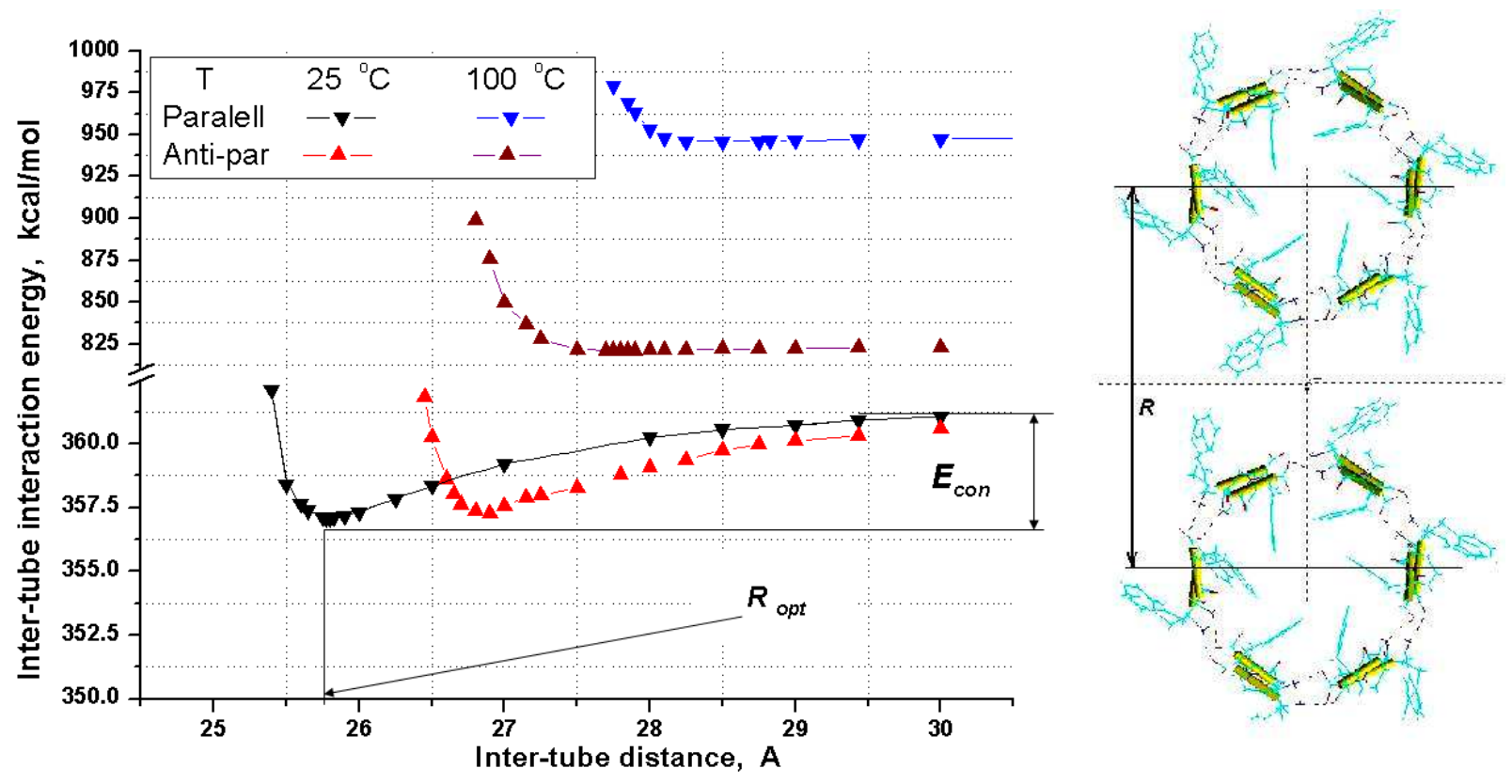

(b)

(c)

Figure S1. Heredia et al. 
(a)

Before annealing

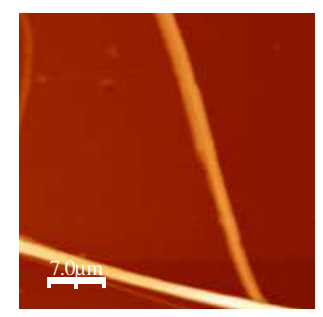

r

Before annealing

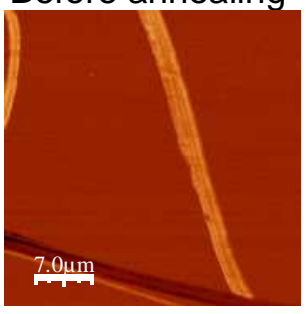

AFM, topography

After $125^{\circ} \mathrm{C}, 1$ hour After $150^{\circ} \mathrm{C}, 1$ hour
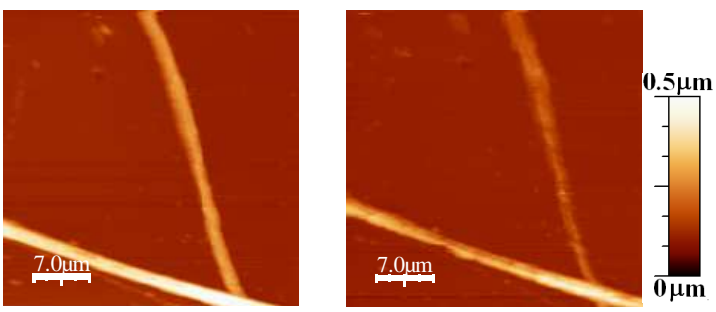

PFM, IPP

After $125^{\circ} \mathrm{C}, 1 \mathrm{hr}$

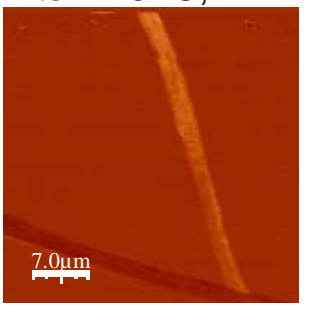

After $150 \stackrel{\circ}{\mathrm{C}}, 1 \mathrm{hr}$

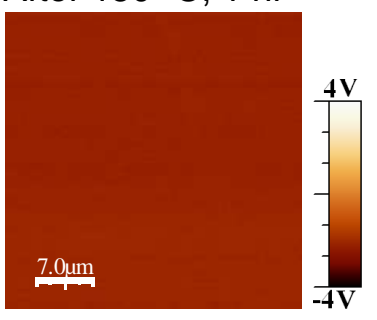

(b)

SEM

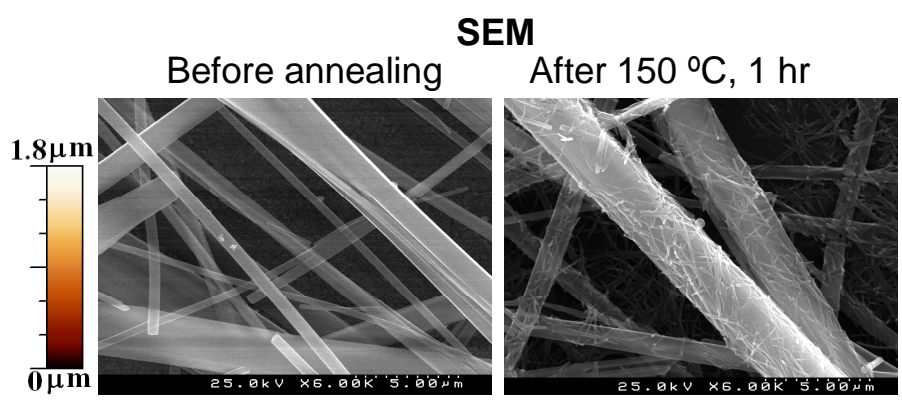

Figure S2. Heredia et al. 
Table.1. Comparison of calculated and observed interplane distances $\left(\mathrm{d}_{\mathrm{cal}}\right.$ and $\left.\mathrm{d}_{\mathrm{obs}}\right)$ and observed relative integrated intensities $\left(\mathrm{I}_{\mathrm{obs}}\right)$ for Debye-Scherrer reflections for the annealed $\left(150^{\circ} \mathrm{C}, 1 \mathrm{~h}\right)$

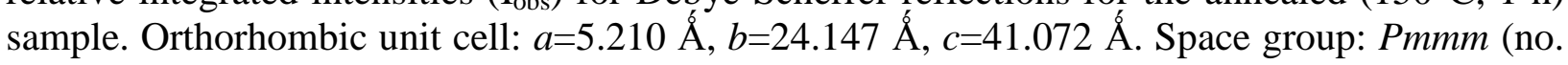
47).

\begin{tabular}{|c|c|c|c|c|c|}
\hline \multicolumn{6}{|c|}{ After treatment at $150{ }^{\circ} \mathrm{C}$, new phase } \\
\hline \multicolumn{3}{|c|}{ Experiment } & \multicolumn{3}{|c|}{ 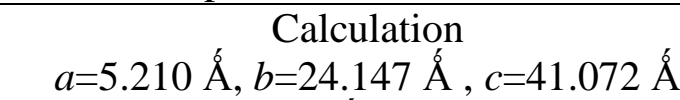 } \\
\hline $2 \Theta_{\text {obs }}{ }^{\circ}$ & $\mathrm{d}_{\mathrm{obs}}, \AA$ & $\mathrm{I}_{\mathrm{obs}}(\%)$ & $2 \Theta_{\text {cal }}, \circ$ & $\mathrm{d}_{\mathrm{cal}}, \AA$ & hkl \\
\hline 7.32 & 12.03 & 100 & 7.31 & 12.07 & 020 \\
\hline 11.24 & 7.86 & 80 & 11.30 & 7.82 & 024 \\
\hline 17.10 & 5.18 & 33 & 17.02 & 5.20 & 044 \\
\hline 17.51 & 5.06 & 42 & 17.53 & 5.05 & 1111 \\
\hline 20.44 & 4.34 & 53 & 20.40 & 4.35 & 131 \\
\hline 22.66 & 3.92 & 76 & 22.72 & 3.91 & 048 \\
\hline 23.84 & 3.74 & 95 & 23.73 & 3.75 & 064 \\
\hline 26.82 & 3.32 & 20 & 26.84 & 3.32 & 0667 \\
\hline 28.17 & 3.16 & 25 & 28.16 & 3.16 & $\begin{array}{llllll} & 0 & 13\end{array}$ \\
\hline
\end{tabular}

Table 2. Condensation energies and optimized distances at different temperatures.

\begin{tabular}{|l|l|l|l|l|l|l|l|}
\hline $\begin{array}{l}\text { Tempe- } \\
\text { rature, } \\
{ }^{\circ} \mathrm{C}\end{array}$ & \multicolumn{2}{|l|}{$\begin{array}{l}\text { Energy of inter- } \\
\text { ring condensation }\end{array}$} & $\begin{array}{l}\boldsymbol{R}_{\text {opt }} \text { of } \\
\text { inter-ring } \\
\text { at E min, }\end{array}$ & $\begin{array}{l}\text { Type of } \\
\text { inter-tube } \\
\text { structure }\end{array}$ & \multicolumn{2}{l|}{$\begin{array}{l}\text { Energy of inter- } \\
\text { tube condensation } \\
\boldsymbol{E}_{\text {con }}\end{array}$} & $\begin{array}{l}\boldsymbol{R}_{\text {opt }} \text { of } \\
\text { inter-tube } \\
\text { at E min, } \AA\end{array}$ \\
\hline & $\mathrm{kcal} / \mathrm{mol}$ & $\mathrm{eV}$ & & & $\mathrm{kcal} / \mathrm{mol}$ & $\mathrm{eV}$ & \\
\hline 25 & 130.3 & 5.7 & 5.45 & Parall & 4.4 & 0.20 & 25.80 \\
\hline & & & & Anti-par & 4.2 & 0.18 & 26.90 \\
\hline 100 & 101.3 & 4.4 & 5.50 & Parall & 2.5 & 0.10 & 28.50 \\
\hline & & & & Anti-par & 2.9 & 0.13 & 27.75 \\
\hline
\end{tabular}

Table 3. Calculation of electric field effect for 2-rings PNT model using UHF PM3 method and HyperChem 8.0.

\begin{tabular}{|c|c|c|c|c|c|c|}
\hline \multirow{2}{*}{\multicolumn{2}{|c|}{$\begin{array}{l}\text { Simulated } \\
\text { electric field } \\
\text { along tube OZ-axis } \\
E_{\mathrm{z}}\end{array}$}} & \multicolumn{2}{|c|}{ Dipole moment } & \multirow{3}{*}{$\begin{array}{l}\text { total } \\
\mathrm{P} \\
\mu \mathrm{C} / \mathrm{cm}^{2}\end{array}$} & \multirow{2}{*}{\multicolumn{2}{|c|}{$\begin{array}{c}\text { Polarizability } \\
\quad \alpha\end{array}$}} \\
\hline & & \multirow{2}{*}{$\begin{array}{l}\text { D total } \\
\text { Debye }\end{array}$} & \multirow{2}{*}{$\begin{array}{l}\mathrm{D}_{\mathrm{z}} \\
\text { Debye }\end{array}$} & & & \\
\hline a.u. & $\mathrm{MV} / \mathrm{cm}$ & & & & $\mu \mathrm{C} / \mathrm{cm}^{2} / \mathrm{V}_{\mathrm{m}} / \mathrm{E}$ & $A^{3}$ \\
\hline 0 & 0 & 42.76 & -42.70 & 4.10 & - & - \\
\hline+0.001 & +5.1422 & 47.71 & -47.63 & 4.54 & 0.44 & 269.29 \\
\hline-0.001 & -5.1422 & 37.89 & -37.78 & 3.61 & 0.49 & 299.89 \\
\hline
\end{tabular}

For comparison see data from literature:

- diphenylalanine (Di-Phe, FF): $\alpha \sim 33.20 \mathrm{~A}^{3}=33.20 * 10^{-24} \mathrm{~cm}^{3}, \mathrm{~V}_{\mathrm{FF}}=282.37 \mathrm{~A}^{3}<<\mathrm{V}_{\mathrm{m}}$ (data from HyperChem 8.0) - beta-Phenyl-L-phenylalanin : $\alpha \sim 27.7 \mathrm{~A}^{3}=27.7 * 10^{-24} \mathrm{~cm}^{3}$

(data from http://www.chemspider.com/Chemical-Structure.143073.html) 